Accepted manuscript of:

S.Janssen \& H. Leemans (1988). Differences in consumer behaviour

between buyers of literature. Poetics 17, 563-575.

https://doi.org/10.1016/0304-422X(88)90012-5

\title{
DIFFERENCES IN CONSUMER BEHAVIOR BETWEEN BUYERS OF LITERATURE
}

\author{
S. JANSSEN and H. LEEMANS *
}

Members of the book trade as well as the theory of communication and advertising presume a positive relationship between attention in the media and sales. This view, however, stands in need of qualification. When the actual purchases of individual buyers of literature are considered, a relationship with attention given in the media is not found in all cases: besides a substantial group of buyers who purchase a title which has received attention, there is also a considerable number of buyers who purchase a title which has received no attention in the media. We assume that these differences in the actual purchases of buyers of literature are related to differences in consumer behavior. The analyses in our paper corroborate this assumption. The groups of buyers distinguished above appear to differ, among other things, as regards their use and appreciation of various sources of information with respect to literature.

\section{Introduction}

Literary publishers and booksellers consider it very important that the media pay attention to their products. They hold the view that the commercial success of a literary book depends to a considerable extent on reviews, interviews with the author and mentions in literary columns. In particular favourable attention is thought to be very influential, but unfavourable attention is preferred to no attention at all: unknown, unloved. In addition, the attention paid toa particular book is presumed to have a sort of 'radiation effect' on the sales of other titles by the author in question.

Empirical research has not shown unequivocally the presumed relation between the attention literary titles receive in the media and their sales. Verdaasdonk (1987) only found a restricted relationship for literary books which received the lion's share of reviewer's attention. We also hold the view that the relationship between attention given in the media and sales should be made more specific.

\footnotetext{
* For his comments on an earlier draft of this paper, we are indebted to Hugo Verdaasdonk. Pieter Nieuwint corrected our English.
} 
When the actual purchases of individual buyers of literature are considered, a relationship with attention given in the media is not found in all cases: there is a substantial group of buyers who purchase a title which has received no attention at all. However, there is also a considerable number of buyers who purchase a title which has received attention. Furthermore, a third group of buyers can be distinguished, who take an intermediate position: they buy a title which has received no attention, but has been written by an author who recently did receive attention in daily newspapers and weekly magazines. This may have something to do with the 'radiation effect' mentioned above.

In this article we will examine if there exist differences in consumer behavior, and in particular differences in the acquisition of information, between buyers who, judging from their actual purchases, seem guided to various degrees by the literary information provided by the media. To be guided by attention in the media presupposes that buyers of literature care about what is written about literature in dailies and weeklies and that they are willing to invest a considerable amount of energy and time in order to get acquainted with it. Therefore, we expect that buyers of a literary title which has received attention in dailies and weeklies, attach greater importance to the information that the media provide; more of ten read those newspapers and magazines in which relatively much attention is paid to literature; and are better informed about the range of literary books available than buyers of a literary book which has received no attention at all. We expect that buyers of a title with only attention given to the author take an intermediate position.

The impact of free publicity and advertisements can be retrieved in theory in the so-called classical hierarchical advertising-models like AIDA, DAGMAR, Roger's innovation model and the models of Lavidge and Steiner. ${ }^{1}$ Each model assumes that an individual buyer has to pass through three stages: as to literary books, in the first place, a prospective buyer has to get acquainted with a particular title, secondly, he has to develop a preference for it, and, finally, he has to make up his mind to buy it. Together, these three phases make up the attitude towards the literary book in question. In the buying process attitude represents a predisposition to behave in a particular way: on the basis of knowledge the consumer develops a preference and, subsequently, a desire to buy. Because we expect differences in the acquisition of information between the groups of buyers defined previously we assume that the filling-in of the models differs.

All advertising models are based on the assumption that literary books are perceived by individual buyers as high involvement products. Petty and Cacioppo (1979) define high involvement as 'the activation of extended problem-solving behavior when the act of purchase or consumption is seen by

\footnotetext{
1 AIDA $=$ Attention-Interest-Desire-Action.
}

DAGMAR = Defining Advertising Goals for Measured Advertising Results. 
the decision maker as having high personal importance or relevance'. High personal relevance occurs when the product has the following characteristics: relatively expensive, complex features, many differences between alternatives, perceiving high risks of making the wrong decision and a strong relationship between product image and self image. High involvement activates extended problem solving: a decision process characterized by the evaluation of many attributes and the sequence knowledge, preference and willingness to buy. Extended problem solving presumes the relatively intensive use of a number of information sources.

Literary books seem to have the characteristics of high involvement products: the phenomenon that buyers of ten discuss literary books is an indication of their perceived importance in the selfimage. In addition, there are many different literary titles available and from earlier research ${ }^{2}$ it appears that in their decision process, buyers of literature use up to nine attributes and up to fourteen sources of information to various degrees.

Daily newspapers and weekly magazines offer the buyer of literature a good opportunity to get acquainted with a large range of recently published literary books. From the large supply of new literary books book reviewers select a limited number for a review. The attention reviewers pay to new titles resembles the relative importance they attach to these titles. In many cases members of the booktrade and consumers regard the choices made by reviewers as the 'right' choices. After all these choices are made by 'connoisseurs'. Therefore it seems plausible that buyers of literature are inclined to adjust their choices from the literary booksupply to the choices made in daily newspapers and weekly magazines. When a buyer gears his choice to the choices made by 'connoisseurs', he not only reduces the risk of making the wrong decision, but also shows 'good' taste.

If the reasoning above is correct, buyers who have purchased a title which received attention in the media must be guided most by reviews and read newspapers and magazines which pay a relatively high amount of attention to literature.

In this article we will examine the expectations and assumptions stated above in section 4. Before we proceed, we will briefly discuss the data collection (section 2) and the relation between attention given in the media and sales (section 3 ).

\section{Data collection}

The data used in this article about buyers of literature were obtained by means of an oral survey, conducted in the period from the end of november 1985 to

2 Leemans and Van Doggenaar (1988) 
February 1986 in nineteen bookshops in six Dutch cities. ${ }^{3}$ If a visitor of one of these bookshops bought a book from one of the UGI-categories ${ }^{4}$ 'literary novels', 'poetry' or 'literary non-fiction', he was asked to cooperate in the survey. This resulted in 727 questionnaires, which meant a response of over $55 \%$. The results of the analysis of the questionnaires present a detailed picture of buyers of literature, which is made up of not only the buying, reading and borrowing behavior and the usual social and demographic characteristics, but also of the behavior regarding information processing and leisure activities, the relative importance buyers attach to various attributes of literary books and last but not least the characteristics of the purchased literary book, such as title, author, price, publishing house.

We did not register the attention given to literature in all newspapers and weekly magazines. We selected those newspapers and magazines which regularly publish about literature and which are read by our respondents. Of each title which received attention in these media, we registered the title, the author, the publisher and the price. Furthermore we registered the name of the newspaper or magazine in which the title in question had received attention. When we say 'attention', we mean a review, an interview, a mention in a literary column, a reference or an advertisement. Finally we counted the number of words wherever possible. Because of the great number of titles which receive attention in the media and the rapidly declining effects of media attention over time, registrations were limited to the last six weeks of 1985 and the first five weeks of 1986 .

\section{The relation between attention given in dailies and weeklies and sales}

We registered the total attention the selected media paid to literary titles. From the questionnaires we obtained data regarding the titles, authors, etc., to a maximum of three literary books which buyers purchased on the spot. Therefore, titles can be categorized as follows:

(1) A title has received attention in the selected media but has not been purchased by the respondents, nor has other work by the author in question.

(2) A title has received attention in the selected media but another title by the same author has been purchased by one or more respondents.

(3) A title has received attention in the media and has also been purchased by one or more respondents.

\footnotetext{
${ }^{3}$ Leemans and Van Doggenaar (1987)

4 'UGI' refers to the Uniform Genre Classification used by almost the entire book publishing fraternity with a view to categorizing their book production.
} 
If there exists a relationship between attention given in the media and the purchase of a title, most attention will be paid to titles from category 3, least attention to titles from category 1 , while titles from category 2 take an intermediate position. Table 1 gives an impression of the outcome.

Table 1

Results of the analysis of differences in mean attention paid to 3 categories of literary titles.

\begin{tabular}{|c|c|c|c|c|c|c|c|}
\hline & \multirow{3}{*}{$\begin{array}{l}\text { Mean } \\
\text { cat } 1\end{array}$} & \multirow{3}{*}{$\begin{array}{l}\text { Mean } \\
\text { cat } 2\end{array}$} & \multirow{3}{*}{$\begin{array}{l}\text { Mean } \\
\text { cat } 3\end{array}$} & \multicolumn{4}{|c|}{ Probability of type I error } \\
\hline & & & & \multirow[t]{2}{*}{$\overline{f \text {-ratio }}$} & \multicolumn{3}{|l|}{$t$-value } \\
\hline & & & & & 1 vs. 2 & 1 vs. 3 & 2 vs. 3 \\
\hline $\begin{array}{l}\text { Total Attention, } \\
\text { made up of: } \\
\text {-reviews or }\end{array}$ & 1.77 & 1.94 & 4.92 & $<0.01$ & & $<0.01$ & $<0.01$ \\
\hline $\begin{array}{l}\text { interviews } \\
\text {-mentions in }\end{array}$ & 0.26 & 0.28 & 0.66 & $<0.01$ & & $<0.01$ & $<0.01$ \\
\hline lit columns & 0.21 & 0.10 & 0.47 & $<0.01$ & $<0.01$ & $<0.01$ & $<0.01$ \\
\hline -references & 0.58 & 0.99 & 2.41 & $<0.01$ & $<0.01$ & $<0.01$ & $<0.01$ \\
\hline -advertisements & 0.72 & 0.58 & 1.37 & $<0.01$ & $<0.05$ & $<0.01$ & $<0.01$ \\
\hline $\begin{array}{l}\text { Attention in } \\
\text { words }\end{array}$ & 715 & 1.322 & 1.822 & $(0.10)$ & & $<0.01$ & \\
\hline
\end{tabular}

In almost all cases the $F$ test points to statistically significant differences between categories. However, the mean attention expressed in the number of words only reveals a difference between purchased titles and non-purchased titles whereas the mean attention given in the media sec suggests a dichotomy between category 1 and 2 on the one hand and category 3 on the other. The same dichotomy arises when the mean number of reviews and interviews is considered. Attention given in the media in the form of mentions in literary columns, references and advertisements constitutes an additional distinction between categories 1 and 2. The results of the one-way analysis of variance presented in table 1 do not contradict the presumed relation between attention given in the media to a specific title and its sales, but they do not show statistically significant differences between non-purchased authors (category 1) and non-purchased titles (category 2) with the exception of certain forms of attention.

\section{Behavioral differences between 3 groups of literary buyers}

On the basis of their purchase at the moment of the survey the respondents have been assigned to one of the following groups:

(1) Buyers of a literary book which has not received attention in dailies and weeklies $(n=253)$ 
(2) Buyers of a literary book which has received no attention, but was written by an author who has received attention in dailies and weeklies. $(n=121)$

(3) Buyers of a literary book which has received attention in dailies and weeklies. $(n=351)$

In this section we shall examine if the three groups of buyers distinguished differ as regards their use and appreciation of various sources of information with respect to literature; the frequency with which they read particular dailies and weeklies, their knowledge of the literary book supply; the extent to which they acquire and read literary books; and the degree to which they take into account a number of attributes and considerations when buying a literary book.

\subsection{The acquisition of information}

Buyers of literature have a number of ways at their disposal to inform themselves about the supply of literary books. The survey contained a list of fourteen sources of information. The respondents were asked whether they make use of the sources of information on the list, and to what extent they regard the various sources of information as important. Each source of information was assigned a score by the respondents ranging from 'not used' to 'very important'.

First we examined if the three groups of buyers distinguished above differ with respect to the number of sources of information they use. A one-way analysis of variance showed that on average each group of buyers makes use of seven to eight sources of information. Application of a factor analysis proved that the original list of fourteen sources of information could be reduced to a more meaningful one consisting of six main sources of information.

Next, we examined whether the three groups of buyers show differences as regards the degree of importance they attach to these six sources of information. By means of a Kruskal-Wallis one-way analysis of variance the mean scores of the three groups on each source of information have been compared. ${ }^{5}$ Because of the ordinal level of the dependent variable we used this non-parametric test instead of the parametric one-way analysis of variance. The Mann-Withney U-test was applied in order to locate differences between groups. ${ }^{6}$ The results of the analyses are given in table 2 .

The results of the Kruskal-Wallis analysis of variance show that the three groups of buyers differ with respect to three sources of information. As regards the mean scores on 'literary columns' and 'bookshop' group 1 differs

\footnotetext{
5 For a description of the Kruskall-Wallis one-way analysis of variance, see Siegel (1956).

${ }^{6}$ For a description of the Man-Whitney U-test, see Siegel (1956).
} 
Table 2

Results of the analysis of differences in the average degree of importance attached to 6 sources of information.

\begin{tabular}{|c|c|c|c|c|c|c|c|}
\hline \multirow{3}{*}{$\begin{array}{l}\text { Source of } \\
\text { information }\end{array}$} & \multicolumn{3}{|c|}{ Mean rank score group } & \multicolumn{4}{|c|}{ Probability of type I error } \\
\hline & \multirow[t]{2}{*}{1} & \multirow[t]{2}{*}{2} & \multirow[t]{2}{*}{3} & \multirow[t]{2}{*}{$H$-ratio } & \multicolumn{3}{|l|}{$U$-value } \\
\hline & & & & & 1 vs. 2 & 1 vs. 3 & 2 vs. 3 \\
\hline Reviews & 325.2 & 356.2 & 392.6 & $<0.01$ & & $<0.01$ & $<0.10$ \\
\hline $\begin{array}{l}\text { Literary } \\
\text { columns }\end{array}$ & 328.1 & 370.3 & 385.7 & $<0.01$ & $<0.05$ & $<0.01$ & \\
\hline Advertisements & 356.8 & 352.3 & 371.1 & & & & \\
\hline Book itself ${ }^{a}$ & 370.5 & 353.9 & 360.7 & & & & \\
\hline Bookshop ${ }^{b}$ & 388.0 & 338.8 & 353.3 & $<0.05$ & $<0.05$ & $<0.05$ & \\
\hline $\begin{array}{l}\text { Family, } \\
\text { friends, etc. }\end{array}$ & 375.2 & 372.2 & 351.0 & & & & \\
\hline
\end{tabular}

\footnotetext{
${ }^{a}$ Book itself $=$ Blurbs, leafing through the book.

${ }^{\mathrm{b}}$ Bookshop = Displays, shopwindow, direct mail, prospects, bookseller's advice.
}

from group 2 and 3. On average the buyers of a book which has received attention in the media or was written by an author who has received attention in the media (groups 2 and 3) regard 'literary columns' as more important than the buyers of a book which has received no attention at all, whereas the latter category of buyers consider 'bookshop' a more important source of information than the two other groups. Taking into account the mean score of 'book reviews', only the difference between group 1 and group 3 is significant in the statistical sense. On average the latter category of buyers attaches a greater importance to 'book reviews'. In this respect the buyers of a book written by an author who has been given attention by the media (group 2) do not differ from the buyers of group 1, whereas the difference between group 2 and 3 is no more than marginal. The three categories of buyers show no differences as regards the importance they attach to the sources of information 'advertisements', 'family, friends, etc.' and 'the book itself'.

\subsection{The reading of dailies and weeklies}

The respondents were asked how often they read particular dailies and weeklies. As regards the newspapers which were included in the survey, three categories can be distinguished: newspapers with a nationwide circulation which pay a good deal of attention to literature, ${ }^{7}$ newspapers with a nationwide circulation which pay little attention to literature ${ }^{8}$ and regional newspapers which also pay little attention to literature. As to the weekly magazines

${ }^{7}$ De Volkskrant, NRC-Handelsblad, Trouw, Het Parool.

8 Algemeen Dagblad, Telegraaf. 
we distinguished two categories: the magazine Vrij Nederland and the other weeklies. We put Vrij Nederland in a separate category, because this magazine pays considerably more attention to literature than any other weekly.

In order to determine if the three groups of buyers vary as regards the extent to which they read media from the five categories distinguished above, we applied a (Kruskal-Wallis) one-way analysis of variance. The results of the analysis are presented in table 3.

Table 3

Results of the analysis of differences in mean reading frequency of 5 categories of media.

\begin{tabular}{|c|c|c|c|c|c|c|c|}
\hline \multirow{3}{*}{$\begin{array}{l}\text { Media- } \\
\text { category }\end{array}$} & \multicolumn{3}{|c|}{ Mean rank score group } & \multicolumn{4}{|c|}{ Probability of type I error } \\
\hline & \multirow[t]{2}{*}{1} & \multirow[t]{2}{*}{2} & \multirow[t]{2}{*}{3} & \multirow[t]{2}{*}{$H$-ratio } & \multicolumn{3}{|l|}{$U$-value } \\
\hline & & & & & 1 vs. 2 & 1 vs. 3 & 2 vs. 3 \\
\hline$A^{\prime \prime}$ & 292.4 & 375.8 & 409.5 & $<0.01$ & $<0.01$ & $<0.01$ & \\
\hline B & 313.6 & 372.3 & 395.5 & $<0.01$ & $<0.01$ & $<0.01$ & \\
\hline $\mathrm{C}$ & 287.6 & 388.2 & 408.7 & $<0.01$ & $<0.01$ & $<0.01$ & \\
\hline $\mathrm{D}$ & 380.6 & 369.0 & 348.2 & $<0.05$ & & $<0.01$ & \\
\hline$E$ & 381.9 & 355.1 & 352.0 & & & $<0.05$ & \\
\hline
\end{tabular}

A $=$ V rij Nederland, $\mathrm{B}=$ Other Weeklies, $\mathrm{C}=$ Newspapers with a nationwide circulation which pay a good deal of attention to literature, $\mathrm{D}=$ Newspapers with a national circulation which pay little attention to literature. $\mathrm{E}=$ Regional newspapers.

In most cases the H-ratio points to differences between the three groups of buyers. Taking into account the mean scores of the media categories A, B and $\mathrm{C}$, a dichotomy arises between group 1 on the one hand, and group 2 and 3 on the other. On average the buyers of the two latter groups appear to read Vrij Nederland, other weeklies and newspapers paying a good deal of attention to literature more frequently than the buyers of a book which has received no attention in the media whatsoever. With respect to the media categories D and E only group 1 and group 3 differ from each other. Regional and nationwide newspapers in which the amount of attention paid to literature is relatively small, appear to be more often read by the buyers of group 1 .

\subsection{Knowledge of the literary book supply}

The degree to which the respondents are acquainted with the range of literary books available was measured as follows. The survey contained a list of six literary books. The respondents were asked to name both the author and the publisher of the books in question. With respect to each book, the respondents obtained a score of 2 when they were able to give both the name of the author and the publishing house, a score of 1 when they were able to name either the author or the publishing firm and a score of zero when neither the correct author nor the correct publishing house was mentioned. Likewise, we showed 
the respondents a list of six literary authors and asked them to mention one book written by each author and the name of the publishing house marketing the title. In a way to the one described above, the respondents could make a score of 2, 1 or 0 with respect to each author. The total score of a respondent ( 24 at most) was considered to be indicative of his/her knowledge of the literary book supply.

A one-way analysis of variance was applied in order to determine if the three groups of literary buyers differ as regards their knowledge of the supply of literary books. The results of this analysis are presented in table 4 .

Table 4

Results of the analysis of differences in knowledge of the literary book supply.

\begin{tabular}{|c|c|c|c|c|c|c|}
\hline \multicolumn{3}{|c|}{ Mean score } & \multicolumn{4}{|c|}{ Probability of type I error } \\
\hline \multirow[t]{2}{*}{ Group 1} & \multirow[t]{2}{*}{ Group 2} & \multirow[t]{2}{*}{ Group 3} & \multirow[t]{2}{*}{$\overline{\text { F-ratio }}$} & \multicolumn{3}{|c|}{ T-value } \\
\hline & & & & 1 VS. 2 & 1 vs. 3 & 2 vs. 3 \\
\hline 5.02 & 6.18 & 6.78 & $<0.01$ & $<0.01$ & $<0.01$ & \\
\hline
\end{tabular}

The F-test points to differences between the three groups of buyers. A two by two comparison of the group means shows a dichotomy between group 1 on the one hand and groups 2 and 3 on the other. On average, the buyers of a literary book which has received attention in the media or was written by an author who has been given attention in the media are better acquainted with the literary book supply than the buyers of a literary book which has received no attention whatsoever in the media.

\subsection{The acquisition of literary books}

Firstly, we checked whether the three groups of buyers show differences as to the average number of literary books they purchase, borrow and read per annum. The results are given in table 5 .

The three groups of buyers do not differ as regards the yearly number of literary books which they borrow from public libraries, family and friends.

Table 5

Results of the analysis of differences in the average number of literary books which is bought. borrowed and read per annum.

\begin{tabular}{|c|c|c|c|c|c|c|c|}
\hline \multirow{3}{*}{$\begin{array}{l}\text { Number of } \\
\text { books }\end{array}$} & \multicolumn{3}{|c|}{ Mean score group } & \multicolumn{4}{|c|}{ Probability of type I error } \\
\hline & & \multirow[t]{2}{*}{2} & \multirow[t]{2}{*}{3} & \multirow[t]{2}{*}{ F-ratio } & \multicolumn{3}{|l|}{ T-value } \\
\hline & & & & & 1 vs. 2 & 1 vs. 3 & 2 vs. 3 \\
\hline Bought & 24.9 & 28.3 & 32.0 & $<0.10$ & & $<0.05$ & \\
\hline Borrowed & 21.5 & 20.8 & 22.9 & & & & \\
\hline Read & 29.0 & 33.4 & 35.5 & & & $<0.05$ & \\
\hline
\end{tabular}


Taking into account the number of literary books which are purchased and read per annum, group 1 appears to differ from group 3. On average, the buyers of a literary book which has received no attention in the media whatsoever, buy and read less literary books than the buyers of a literary title which did receive media attention. The buyers of group 2 take an intermediate position.

The decision of buyers to purchase a certain title can be affected by a number of attributes, for instance the price and the topicality of the book. We included a list of nine possible attributes in our survey. The respondents were asked to indicate to what extents they regard each of these attributes as important when buying literary books. The respondents assigned a score to each attribute ranging from 0 (unimportant) to 4 (very important).

First, we checked whether the three groups of buyers differ as to the number of attributes and considerations which they take into account in deciding to purchase a literary book. A one-way analysis of variance showed that the three groups do not differ in this respect.

Next, we applied a Kruskall-Wallis one-way analysis of variance in order to determine if the three groups of buyers vary as regards the degree of importance they attach to specific attributes and considerations. The results of this analysis are given in table 6.

\section{Table 6}

Results of the analysis of differences in average degree of importance attached to 9 attributes and considerations.

\begin{tabular}{|c|c|c|c|c|c|c|c|}
\hline & \multicolumn{3}{|c|}{ Mean rank score group } & \multicolumn{4}{|c|}{ Probability of type I error } \\
\hline & \multirow[t]{2}{*}{1} & \multirow[t]{2}{*}{2} & \multirow[t]{2}{*}{3} & \multirow[t]{2}{*}{$H$-ratio } & \multicolumn{3}{|l|}{$U$-value } \\
\hline & & & & & 1 vs. 2 & 1 vs. 3 & 2 vs. 3 \\
\hline Prize & 373.6 & 373.8 & 370.4 & & & & \\
\hline Get-up & 355.8 & 356.6 & 370.4 & & & & \\
\hline Content & 375.1 & 352.0 & 357.1 & & & & \\
\hline Topicality & 339.7 & 348.1 & 389.1 & $<0.05$ & $<0.05$ & $<0.05$ & \\
\hline $\begin{array}{l}\text { Attention in } \\
\text { media }\end{array}$ & 333.9 & 348.1 & 389.1 & $<0.01$ & & $<0.01$ & $<0.05$ \\
\hline $\begin{array}{l}\text { Advice } \\
\quad \text { bookshop }\end{array}$ & 378.3 & 343.3 & 356.7 & & & & \\
\hline $\begin{array}{l}\text { Advice family, } \\
\text { friends, etc. }\end{array}$ & 365.6 & 365.6 & 360.3 & & & & \\
\hline $\begin{array}{l}\text { Reputation } \\
\text { author }\end{array}$ & 347.3 & 363.0 & 372.3 & & & & \\
\hline $\begin{array}{l}\text { Reputation } \\
\text { publisher }\end{array}$ & 341.6 & 328.6 & 387.1 & $<0.01$ & & $<0.01$ & $<0.01$ \\
\hline
\end{tabular}

Table 6 shows that the three groups of buyers differ as to the importance they attach to certain factors and considerations. In comparison with the 
buyers of group 1, the buyers of group 3 pay more attention to the question whether a book was published recently, whether it attracted the attention of the media and by which publishing house the book was brought out. As regards the extent to which 'attention in the media' and 'name of publishing house' are looked upon as important criteria in deciding whether or not to buy a certain book, group 3 differs from group 2 as well. The buyers of group 1 and 2 only differ with respect to the importance they attach to the question whether a book has been published recently.

As mentioned in section 2, visitors of a bookshop were asked to cooperate in the survey, after they had bought a literary book. We asked the respondents if they had read the book which they purchased just now and whether this was the first time they had bought a book by the author in question. As to the first question the buyers of group 1 and 2 appear to differ from group 3. Compared with the latter group, a larger proportion of the buyers in group 1 and 2 purchased a book which they had read previously. With respect to the second question all 3 groups differ. The proportion of buyers who for the first time purchased a work by a certain author appears to be the smallest in group 2 and the biggest in group 1, whereas group 3 takes up a middle position.

Finally, we wanted to know whether the three groups of buyers show differences in level of education and budget for leisure activities. Regarding their budget for leisure activities the three groups show no differences. With respect to educational level group 1 appears to differ from group 3. A bigger proportion of the latter category of buyers received a university education.

\section{Summary and conclusions}

Members of the booktrade as well as the theory of communication and advertising presume a positive relationship between attention in the media and sales. The results of the analysis in section 3 do not contradict this assumption: titles which were purchased by one or more respondents received more attention than titles or authors which were not purchased. However, there are hardly any differences in attention between non-bought titles and non-bought authors.

The mere fact that approximately one in three buyers purchases a title although no attention has been paid to it in daily newspapers and weekly magazines puts the relationship assumed above in perspective: the stimuli in the media did not result in purchases within this group. This phenomenon becomes more relevant if these buyers differ in their consumer behavior from buyers of titles which did receive attention. In that case authors, publishers and booksellers are not only less dependent on attention in the media but might also adapt to behavioral differences. 
The analyses in section 4 show that there are behavioral differences between buyers who bought a literary book which has received attention in dailies and weeklies (group 3) and buyers who bought a book without attention having been paid to it (group 1). Buyers who bought a title which has received no attention, but has been written by an author who recently did receive attention (group 2) take a somewhat unclear intermediate position. Roughly speaking, they bear the greatest resemblance to the buyers of group 3 .

The purchase of a literary book is the outcome of a decision process in which the acquisition of information plays an important role. Therefore, we assumed a relationship between actual purchases and the extent to which literary buyers use various sources of information. Our findings corroborate this assumption: on average, buyers who judging from their purchases seem less guided by attention in the media regard reviews and literary columns as less important sources of information than the two other groups. On the other hand, they attach more importance to information from the bookshop.

These results do not imply that group 1 uses information from the bookshop as a substitute for reviews and literary columns. When we take a closer look at the ranking order of the information sources, it appears that each group regards reviews and literary columns as the main sources of information, followed by informal information sources like family and friends. Blurbs and leafing through the book are considered less important and for each group the bookshop represents the least important source of information.

It is well known that human perception is subjective and selective. The amount of literary information which literary buyers acquire through the media depends, among other things, on their interest in literature and the newspapers and magazines they read. We assumed that the 3 groups of buyers read different newspapers and weekly magazines. The analysis shows that buyers who purchased a book which received attention (groups 2 and 3) more often read those newspapers and weekly magazines in which relatively much attention is paid to literature. This might be an important cause of the established differences in knowledge regarding the available literature between group 1 and groups 2 and 3. Our findings are in line with the classical hierarchical advertising models, where attention precedes knowledge and liking.

In the decision process a prospective buyer evaluates several attributes of titles and authors. This evaluation process contains elements of information processing. Therefore, differences in the acquisition of information can be retrieved in the evaluation of attributes. The greater the importance a literary buyer attaches to information provided by the media, the more attention he will pay to this information and, consequently, the greater the chance that he eventually purchases one of those titles that have received attention in the media.

For publishers and booksellers it is important to know if the three dis- 
tinguished groups of buyers on average purchase the same number of literary books. It appears that buyers of a title which has received attention in the media buy and read more literary books. Nevertheless, the fear of publishers that their products will be ignored by the media, is only partly justified: there are also buyers who purchase literary books which have not received attention and who behave in a different way. Although these buyers are smaller in number and buy less literary books, they represent a substantial market.

\section{References}

Colley, R.H., 1961. Defining advertising goals for measured advertising results. Association of National Advertisers: New York.

Lavidge, R.J. and G.A. Steiner, 1961. A model for predicting measurements of advertising effectiveness. Journal of Marketing 25, 59-62.

Leemans, H. and J. van Doggenaar, 1987. Subdivisions of booksupply made by individual buyers of literature. Poetics 16, 255-268.

Leemans, H. and J. van Doggenaar, 1988. Who buys literary books? A research of the literary bookmarket. Internal report, Katholieke Universiteit Brabant.

Petty, R.E. and J.T. Cacioppo, 1986. The elaboration likelihood model of persuasion. In: L. Berkowitz (ed.), Advances in experimental social psychology, Vol. 14, 123-205. New York: Academic Press.

Petty, R.E., J.T. Cacioppo and D. Schumann, 1983. Central and peripheral routes to advertising effectiveness: The moderating role of involvement. Journal of Consumer Research 10, 134-148.

Rogers, E.M., 1962. Diffusion of innovations. Free Press: New York.

Siegel, S., 1956. Nonparametric statistics for the behavioral sciences. McGraw-Hill: New York.

Strong, K., 1925. The psychology of selling. McGraw-Hill: New York.

Verdaasdonk, H., 1987. Effects of acquired readership and reviewers' attention on the sales of new literary works. Poetics 16, 237-253. 